\title{
The Thinking of P.E Teaching Reforms of Junior College Students - for Example by the Qingdao University of Science and Technology
}

\author{
Feifei $\mathrm{Li}^{1}$ \\ ${ }^{1}$ The Physical Education Teaching and Research Office of Qingdao Science and Technology University, Gaomi, \\ China
}

Received: May 12, 2020

doi:10.5539/ass.v16n6p53
Accepted: May 21, $2020 \quad$ Online Published: May 31, 2020

URL: https://doi.org/10.5539/ass.v16n6p53

\begin{abstract}
The P.E teaching reforms are in full swing in colleges, and the P.E teaching reforms of Junior college students are gradually going deeply. The P.E teaching reforms need to break the inherent and traditional mode, improve the students' learning interests, enrich the contents of physical education, play teachers' professional knowledge and skills, establish a scientific and comprehensive evaluation system of physical education learning and establish a new type of physical education with the idea of "happy sports" and "lifetime sports".
\end{abstract}

Keywords: P.E teaching, learning interest, teaching evaluation, happy sports, lifetime sports

\section{The Preface}

August sixth, 2002, the "Teaching guidelines for physical education courses in national general colleges and universities" issued by the ministry of education caused a strong response across the country. By 2003, it had been carried out by all the general universities in the country. The article 8 of the guidelines definitely pointed out that: "According to the overall requirements of school education and the self-regularity of P.E curriculum, we should establish all kinds of P.E curriculum for all the students. And we can regroup the students in class to satisfy the requirements of them from different levels and interests by breaking previous departments and class organizational systems. We should attach importance to the combination of theory and practice, pay attention to permeate the relevant theoretical knowledge in sports practical teaching, and, using various forms and modern teaching means, arrange nearly $10 \%$ contents of theoretical teaching (about 4 periods per semester) to expand the scope of the P.E knowledge and improve the students' cognitive ability." Conforming to the new guidelines, although the P.E teaching reforms of Chinese colleges have made some progress, there also are many problems need to be settled. Especially for junior college students, they spend less time at school and there is a certain gap between them and undergraduates even graduate students in knowledge and cultural level. At the same time, they have their own characters in physical quality and learning attitude, therefore, the P.E teaching reforms for junior college students need deeper investigation and thoughts.

\section{Research Objects and Methods}

\section{[1]. Research Objects}

The research objects are mainly P.E teaching of junior college students from Qingdao University of Science and Technology.

[2]. Research methods

[3]. Literature Review Method

Search on relevant websites such as China Journal Net to consult nearly 20 years of relevant papers. At the same time, consult relevant P.E teaching books in the libraries such as the library of Qingdao University of Science and Technology and the library of Qingdao University.

[4]. Expect investigation

Investigate the P.E scholars and professors inside and outside the school.

[5]. Method of comparative study

First, summarize the P.E teaching before the teaching reforms of junior college students and find out the problems in P.E teaching. Then, analyze and summarize the P.E teaching in recent two years after the teaching 
reforms of junior college students. By contrasting the differences between before and after P.E teaching reforms, there is great significance of P.E teaching for the junior college students of Qingdao University of Science and Technology.

\section{Analysis and Discussion}

\subsection{The Problems of the P.E Teaching Before the P.E Teaching Reforms}

\subsubsection{Single Teaching Content}

Teaching content is the major information between students' learning and teachers' teaching. In this process, the transmission of information between them is conscious. Under the new curriculum reform, people attach more importance to the ideas of generative teaching and get new realization of teaching content. The teaching content plays a leading role in the whole process.

Before the P.E teaching reform of Qingdao University of Science and Technology, first year junior college students' P.E teaching content is mainly the theories and techniques of junior Changquan second way, standing long jump, girls' 800 meters and boys' 1000 meters in the first semester. In the second semester, the main teaching content is the theories and techniques of athletics, girls' sit-up and boys' push-up. Throughout the school year, the teaching content is very single. It is always invariable before the reforms. The theoretical system of P.E teaching and structure of subject matter conforming this tradition lack the overall breakthrough between theory teaching and practical teaching, teaching thought and teaching knowledge, teaching structure and teaching content.

\subsubsection{Students Are Not Motivated to Study}

Students occupy the main position in the teaching process. Teaching should be student-based. Logically speaking, "external causes" also need "internal causes" to play a decisive role. Even if the teacher tries hard to teach seriously, if the student does not actively study, there is still no good teaching effects. Before the reform of P.E teaching, the school's teaching content mainly is junior Changquan second way in winter. Many students were not interested in a single junior changquan second way, and because students learned dull junior changquan second way outdoors in winter. Students felt very cold and the learning environment is relatively poor; the second semester is mainly to study track and field and other content. For college students, track and field and other sports are the projects that they have been studying from elementary school to high school. Most of the students have already lost interests in running, long jumps and even someone have been bored. The single content of P.E teaching, the lack of attractiveness, the fact that junior college students have the characteristics of low learning consciousness and lack of self-discipline, taking all the factors into consideration, students 'enthusiasm for learning is not high.

\subsubsection{Teachers' Professional Knowledge and Skills Are Not Utilized}

Teachers are dominant throughout the teaching process. The P.E teachers of the school have different majors in their studies. They have various sports such as basketball, football, volleyball, badminton, track and field, sports, aerobics, and so on. They have been systematically studying their own proprietary projects for many years. They have rich theoretical knowledge, technical skills, and high scientific research capabilities. Before the reform, no matter what sports teachers learned or were good at, they must "one size fits all" for sports teaching such as long-term boxing and track and field. It has some teaching effects that P.E teachers seriously taught, loved the dedication, cared for students, taught and educated people, however, if the sports teacher of the football major teaches track and field and the second long boxing and this is undoubtedly a kind of lose to its sports skills and teaching talents. After many years of professional theoretical knowledge and skills learning, he did not realize the sense of achievement of professional projects of P.E teaching in the teaching process. In the entire sports teaching, the school can not do its best. It is a pity and regret.

\subsubsection{The Teaching Evaluation Is One-Sided}

There is no teaching without evaluation. P.E teaching as a part of college teaching has its own uniqueness. P.E teaching evaluation is also more unique than the teaching of other subjects. Before the reform of P.E teaching, the evaluation of P.E teaching for junior college students mainly included three aspects: one was the usual attendance and classroom performance, the other was two or so quality tests, and the third was the examination results such as the two-way long boxing set of actions. Examination evaluation has a certain one-sidedness. It pays more attention to terminal evaluation and ignores diagnostic evaluation and process evaluation. In P.E teaching, evaluation methods are not scientific, and they can not keep up with the learning status of each student in time. First, student-oriented sports teaching is not in place. Once again, we can not grasp whether the students 'physique, quality, and skills have been improved through the study of physical education teaching. There is not 
enough reflection in teaching, and we can not adjust or improve teaching content, teaching methods and teaching methods in time.

\subsection{The Effects That P.E Teaching Reforms Brought}

\subsubsection{Enrich the Teaching Content}

After the reform of P.E teaching, the teaching content has undergone earth-shaking changes. It broke the original traditional sports teaching model and no longer staid. And the teaching content changed from the original single one to specific sports teaching, including sports health, basketball, football, volleyball, ping-pong, badminton, sanda, aerobics, sports dance and other sports. Besides, in each learning of P.E project, in addition to teaching basic technical skills, it also includes theoretical courses such as the history, current situation, and future development trends of the project as well as the project's sports appreciation, referee's law, prevention and treatment of sports injuries, physical fitness exercises, especially core strength training, sports nutrition and health care that students care about. This greatly enriched the P.E teaching content and students can learn more knowledge through learning. And students learn different projects in the first semester and the second semester, so that students can learn at least two sports skills in a limited learning time, laying the foundation for "lifelong sports."

\subsubsection{Increased Students' Enthusiasm for Learning}

Interest is the best teacher. Students have chosen sports courses of interest to them, and the enthusiasm for learning has greatly increased. Through teaching found that after the students 'enthusiasm increases, they will devote themselves fully to the classroom learning. The learning attitude is very correct, and they exercise actively in the process of learning. If they encounter problems that are not understood, they can communicate with the teacher in time. And they study sports skills relatively well. After the learning enthusiasm is improved, not only in the class performance, they also have a good learning effects in the extracurricular .For example, in the classroom learning, the former teacher-led teaching form of explanation was changed, and the learning forms such as group learning, student mutual evaluation, and promoting learning through competition were added, thus improving students' learning initiative and teamwork ability. For example, before class, in addition to summarizing the content of this class, commenting and affirming the students 'learning, allowing them to experience the sense of achievement in learning, the P.E teacher will also arrange after-school homework to request students offer to practice what they have learned after class and use the network resources to learn relevant content by themselves. And when the next class, we inspected and found that the students have basically completed the after-school work and mastered the technical skills very well. Other students do not need teachers to remind or emphasize and they will actively find knowledge and information related to this sport to enrich their own sports vision. Students improve their enthusiasm, are willing to carry out sports learning, learn in happiness and experience the fun brought by learning, which make the concept of "happy sports" go deep into students' hearts. They are obvious for the improvement of teaching effects.

\subsubsection{Play the Teachers' Professional Knowledge and Skills}

Han Yu in the "the division said" he wrote "Teacher, is the person who preaches, teaches students knowledge and answer students' questions." This mainly pointed out that teaching is a comprehensive process: preaching, teaching and answering. After the P.E teaching reforms, P.E teachers can teach their own professional theories and skills that they have studied many years, so it is a piece of cake for them to teach. Teachers' powerful professional theories and skills are played incisively and vividly in teaching. And at the same time, students are convinced by the teachers' professional level that they have expressed in class and prefer to learn to improve their sports skills.

\subsubsection{Scientific and Comprehensive Teaching Evaluation Was Carried Out}

After P.E teaching reforms, teaching evaluations mainly include three parts: diagnostic, process and terminal evaluation. Diagnostic evaluation, process evaluation and terminal evaluation accounted for 10 percent, 30 percent and 60 percent of the total score respectively. Diagnostic evaluation was conducted during the first P.E class and the main purpose of the students' evaluation is to know the students' initial level or current situation of physical quality, basic knowledge and specific technique etc. before the P.E study of this semester; And it also can know students' learning interests, motives, wishes and requirements etc. about the P.E classes they have. According to these actual situations of the students, we can scientifically draw up or remake P.E teaching plans of this semester and specifically arrange teaching content and methods. Process evaluation runs through the whole process of P.E teaching. For each class or stage of teaching, teaching tasks should be taken as the criteria for evaluation .Feeding back the evaluation results to students can let them realize their advantages or 
disadvantages, motivate or urge them to learn better. At the same time, teachers can also feed back and teach the relevant information compared and adjusted, which provides the basis for subsequent teaching. Terminal evaluation is carrying out tests at the end of the term of P.E teaching and we can evaluate the teaching qualities and effects by the tests results, which is mainly in order to evaluate students' P.E grades. Although these three teaching evaluations are different from each other, they are also related, to some degree. In other words, they are an organic whole. We have to make the evaluations after P.E teaching reforms more comprehensive and scientific, focus on each student especially their progress and make P.E teaching change from "cultivate students of ability" to "educate students" by using teaching and evaluation methods reasonably.

\section{Conclusions and Suggestions}

\subsection{Conclusions}

All the time, junior colleges students' P.E teaching of Qingdao University of Science and Technology takes "Junior changquan second way" and "track and field athletics" as the main contents and takes the mastery of skills as the final learning evaluation, which has a disadvantage to some extent. In order to adapt the requirements of the new curriculum reforms, we carried out the P.E teaching reforms of junior college students and achieved some success. Through the P.E teaching reforms, firstly, they can arouse students' learning interests and enthusiasm, make students study spontaneously and master at least two sports skills finally; secondly, they can enrich the contents of P.E teaching and adapt the requirements of students; lastly, they can improve the P.E teaching evaluation system so that we can evaluate students' studies more comprehensively, reasonably and scientifically.

\subsection{Suggestions}

Although P.E teaching reforms for junior college students in Qingdao University of Science and Technology have made some progress, further practices and researches are still needed, for instance, establishing teaching methods of "integration in and out of class", trying new teaching means like "flipped classroom" which will further improve the students' learning enthusiasm and learning effect, is beneficial to the physical education of college students and "promoting teaching".

\section{References}

Hu, H. B. (2008). Research on the Present Situation and Development Countermeasures of Public Sports Options Course in Anhui Normal Colleges and Universities (Master's thesis). Suzhou: Suzhou University.

Li, H. Z. (2013). A Study on the P.E Teaching Mode of "Intra-curricular Integration" in Beijing Independent College (Master's thesis). Beijing: Capital Institute of Physical Education.

Li, L. P., Zeng, S. S., \& Liu, Z. H. (2008). Rethinking the Reform of Physical Education Teaching in Colleges and Universities. Journal of Shenyang Institute of Physical Education, 27(4), 89-92.

Mao, X. R. (2006). Reflection on the Reform of P.E Teaching in Colleges and Universities. Journal of Shandong Institute of P.E, 22(5), 118-120.

Pan, Y. (2015). Analysis of Factors and Countermeasures Affecting the Development of Physical Education Teaching in Colleges and Universities in China. Sports Vision, 27(5), 224-225.

Wang, B. (2008). On the Reform of Physical Education Teaching in Colleges and Universities. Journal of Changzhi College, 25(2), 74-77.

\section{Copyrights}

Copyright for this article is retained by the author(s), with first publication rights granted to the journal.

This is an open-access article distributed under the terms and conditions of the Creative Commons Attribution license (http://creativecommons.org/licenses/by/4.0/). 